\title{
CYSTIC HYGROMA IN ADULTS - A RARE CASE REPORT
}

Krushna Chandra Mallick ${ }^{1}$, Rabindra Kumar Khatua ${ }^{2}$, Subhalaxmi Routray ${ }^{3}$, Anasuya Lenka ${ }^{4}$

\section{HOW TO CITE THIS ARTICLE:}

Krushna Chandra Mallick, Rabindra Kumar Khatua, Subhalaxmi Routray, Anasuya Lenka. "Cystic Hygroma in Adults- A Rare Case Report". Journal of Evolution of Medical and Dental Sciences 2014; Vol. 3, Issue 10, March 10; Page: 2561-2564, DOI: 10.14260/jemds/2014/2173

ABSTRACT: Cystic hygroma (lymphangioma) is a benign congenital malformation of the lymphatic system that occurs in infants and children younger than two years of age. It is rarely seen in adults. Occurrence in adults is uncommon, and only few cases of adult lymphangioma have been reported in the literature. Here we present a rare case of cystic hygroma in a 52 year old patient who presented with a swelling in the neck. Computed tomography revealed presence of cystic masses in the lesion. After total excision of the mass, histopathological diagnosis of cystic lymphangioma was made. After an uneventful postoperative period patient was discharged. No recurrence has occurred since then. This case report discusses the differential diagnoses and up-to-date management of cystic hygroma in adults. The objectives of this report are to discuss about the clinical presentation, diagnosis, pathologic findings and management of this malformation.

KEYWORDS: Cystic hygroma, lymphangioma, lymphatic system, congenital malformation.

INTRODUCTION: Cystic hygroma (lymphangioma) is a benign congenital malformation of the lymphatic system that occurs as a result of sequestration or obstruction of developing lymphatic vessels.1,2 These lesions are usually discovered in infant or children younger than two years of age. Occurrence in adults is uncommon, and fewer than 150 cases of adult lymphangioma have been reported in the literature..$^{3-5}$

Cystic hygroma can be classified into septated (multiloculated) or non-septated single cavity (non-loculated) types. Presentation in adulthood is rare and the cause is uncertain, although trauma and upper respiratory tract infection have both been suggested as possible triggers for onset.6, 7

Diagnosis in adults is considered to present a greater challenge than in children and initial misdiagnosis, frequently as branchial cleft cysts as in the case reported here, is common.6,8 Definitive diagnosis is usually based on post-operative histological findings.

Here we present a case of cystic hygroma in an adult patient and discuss the management options for such a presentation.

CASE REPORT: A 52-year-old woman was referred to our clinic with history of a slowly enlarging mass on the left side of her neck (Figure 1) since last ten months. She noted discomfort and mild pain while turning her head to the left side. She was further asymptomatic. Physical examination revealed a soft, smooth and mobile mass measuring about $10 \mathrm{~cm}$, in the left supraclavicular fossa and left lateral side of neck. In fine needle aspiration cytology (FNAC), yellowish fluid was aspirated and showed the presence of mature lymphocytes and histiocytes. Computed tomography of the neck revealed presence of a lobulated cystic mass extending from the root of neck to the upper part of lateral neck, deep to the left sternomastoid and lateral to the carotid and jugular vessels (Figure 2). Excision of the mass was performed under general anesthesia. Histopathological diagnosis was cystic lymphangioma which was supported with massively dilated lymphatic spaces lined by endothelial 
cells and separated by intervening connective tissue containing lymphoid aggregates (Figure 3 ). Follow-up at 12, 24 and 36 months showed no recurrence.

DISCUSSION: Cystic hygromas believed to arise from a congenital malformation of the lymphatic system. Failure of communication between the lymphatic and the venous pathways leads to accumulation of lymph. Most cystic hygromas present in-utero or in infancy. Therefore most of the literatures on management consider pediatric cases. The effect of these lesions depends on their position and relationship to surrounding structures. Although the most common adult presentation is of a painless lump in an otherwise asymptomatic patient ${ }^{6}$, rapid enlargement over a short period of time has frequently been reported ${ }^{8}$ and major structures such as the larynx, trachea, esophagus, brachial plexus and great vessels have known to be compressed or incorporated within the lesion ${ }^{9}$. In this case the lesion had doubled in size over a period of 4 months and had caused a restriction of neck movement; others have reported presentation with pain, hoarseness, dysphagia and breathlessness. ${ }^{1,9,10}$

Lymphangiomas are best visualized by magnetic resonance imaging (MRI). The high water content allows lymphangiomas to appear hyperintense on T2-weighted Images. ${ }^{10}$ The other imaging methods are Doppler ultrasonography and computed tomography (CT).Complete surgical excision has traditionally been considered the treatment of choice for cystic hygroma.11-14 However, several authors have suggested that sclerotherapy (with alcohol, bleomycin and OK-432) may be a more appropriate first-line therapy. ${ }^{15,16}$ Intravenous cyclophosphamide has also been used, with some success, in recurrent lesions following surgery. ${ }^{17}$

This case was unusual in that a large cervical cystic hygroma presented de-novo in an adult with no history of trauma or upper respiratory infection. This presented a diagnostic challenge due to the rarity of the lesion in adults. Complete excision was successful and the prognosis is good. The authors would like to emphasize the importance of pre-operative imaging and surgical excision in the management of these lesions.

\section{REFERENCES:}

1. Bloom DC, Perkins JA, Manning SC. Management of lymphatic malformations. Curr Opin Otolaryngol Head Neck Surg 2004; 12: 500-4. PMid: 15548907.

2. Naidu SI, McCalla MR. Lymphatic malformations of the head and neck in adults: a case report and review of the literature. Ann Otol Rhinol Laryngol 2004; 113: 218-22. PMid: 15053205.

3. Gow L, Gulati R, Khan A, Mihaimeed F (2011). Adult-onset cystic hygroma: a case report and review of management. Grand Rounds 11: 5-11. doi:10.1102/1470-5206.2011.0002.

4. Sherman BE, Kendall K. A unique case of a large cystic hygroma in the adult. Am J Otolaryngol 2001; 22: 206- 210.

5. Suk S, Sheridan M, Saenger JS. Adult lymphangioma: a case report. Ear Nose Throat J 1997; 76: 881-883.

6. Schefter RP, Olsen KD, Gaffey TA. Cervical lymphangioma in the adult. Otolaryngol Head Neck Surg 1985; 93: 65-69. PMid: 3920626.

7. Antoniades K, Kiziridou A, Psimopoulou M. Traumatic cervical cystic hygroma. Int J Oral Maxillofacial Surg 2000; 29: 47-8.

8. Kraus J, Plzak J, Bruschini R et al. Cystic lymphangioma of the neck in adults: a report of three cases. Wiener Klin Wochenschr 2008; 120: 242-5. doi:10.1007/s00508-008-0950-4. 
9. de Casso Moxo C, Lewis NJ, Rapado F. Lymphangioma presenting as a neck mass in the adult. Int J Clin Pract 2001; 55: 337-8. PMid: 11452685.

10. Woods D, Young JE, Filice R, Dobranowski J. Late-onset cystic hygromas: the role of CT. Can Assoc Radiol J 1989; 40:159-161.

11. Riechelmann H, Muehlfay G, Keck T, Mattfeldt T, Rettinger G. Total, subtotal, and partial surgical removal of cervicofacial lymphangiomas. Arch Otolaryngol Head Neck Surg 1999; 125: 643-8. PMid: 10367920.

12. Mandel L. Parotid area lymphangioma in an adult: case report. J Oral Maxillofacial Surg 2004; 62: 1320-3. doi:10.1016/j.joms.2003.12.040.

13. Morley S, Ramesar K, Macleod D. Cystic hygroma in an adult: a case report. J R Coll Surg Edinb 1999; 44: 57-8. PMid: 10079671.

14. Oakes M, Sherman B. Cystic hygroma in a tactical aviator: a case report. Mil Med 2004; 169: 985-7. PMid: 15646192.

15. Sichel JY, Udassin R, Gozal D, Koplewitz BZ, Dano I, Eliashar R. OK-432 therapy for cervical lymphangioma. Laryngoscope 2004; 114: 1805-9. doi:10.1097/00005537-200410000-00024. PMid: 15454776. 10 L. Gow et al.

16. Smith MC, Zimmerman MB, Burke DK, et al. Efficacy and safety of OK-432 immunotherapy of lymphatic malformations. Laryngoscope 2009; 119: 107-15. doi:10.1002/lary.20041. PMid: 19117316.

17. Turner C, Gross S. Treatment of recurrent suprahyoid cervico facial lymphangioma with intravenous cyclophosphamide. American Journal of Pediatric HematologyOncology.1994: 16(4); 325-328

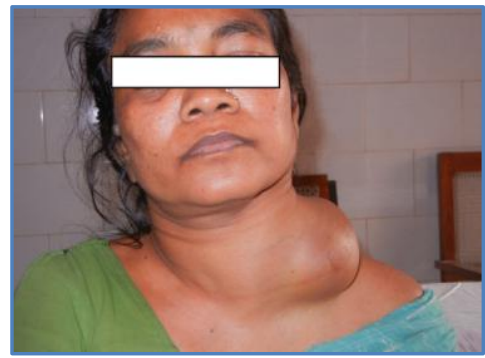

Fig. 1: Neck swelling in left supraclavicular space

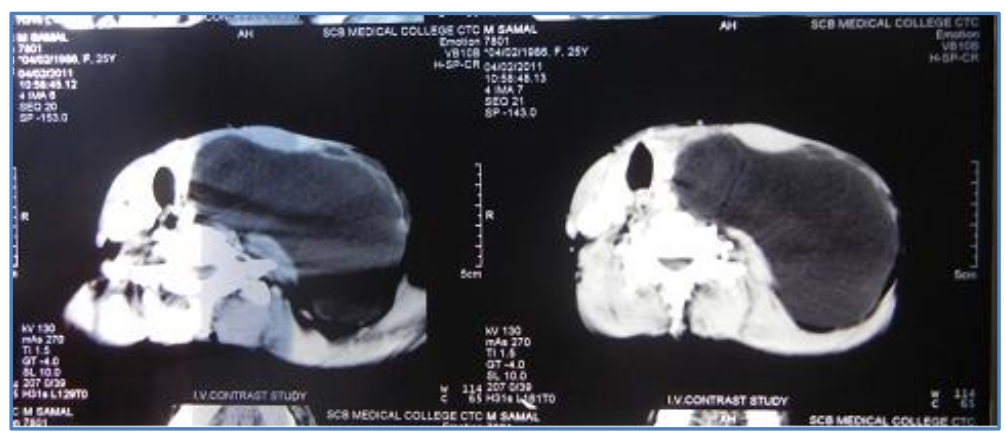

Fig. 2: CT SCAN: 8x9x10 cm lobulated cystic mass deep to the right sternomastoid and lateral to the carotid and jugular vessels 


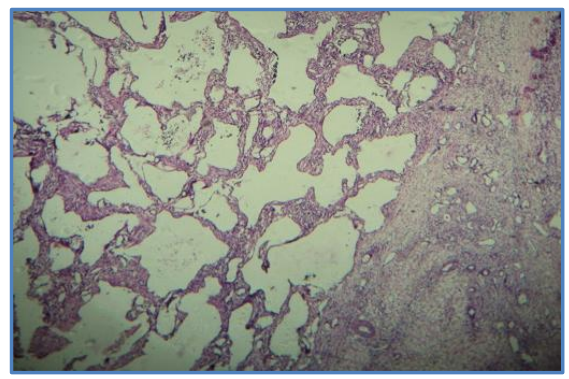

Fig. 3: Histological findings: Dialated lymphatic spaces lined by endothelial cells and separated by intervening connective tissue containing lymphoid aggregates

\section{AUTHORS:}

1. Krushna Chandra Mallick

2. Rabindra Kumar Khatua

3. Subhalaxmi Routray

4. Anasuya Lenka

\section{PARTICULARS OF CONTRIBUTORS:}

1. Associate Professor, Department of E. N. T, S. C. B. Medical College and Hospital, Cuttack.

2. Senior Resident, Department of E. N. T, S. C. B. Medical College and Hospital, Cuttack.

3. Assistant Professor, Department of E. N. T, S. C. B. Medical College and Hospital, Cuttack.

4. Post Graduate Student, Department of Pathology, S. C. B. Medical College and Hospital, Cuttack.

\section{NAME ADDRESS EMAIL ID OF THE} CORRESPONDING AUTHOR:

Dr. Rabindra Kumar Khatua, C/o. Laxmidhar Dash, Malhasahi, Mangalbag, Cuttack - 753001, Odisha.

E-mail: rabimkcgian83@gmail.com

Date of Submission: 01/02/2014. Date of Peer Review: 03/02/2014. Date of Acceptance: 20/02/2014. Date of Publishing: 05/03/2014. 